\title{
Glucose control in diabetes during home confinement for the first pandemic wave of COVID-19: a meta-analysis of observational studies
}

\author{
Giovanni Antonio Silverii ${ }^{1}\left[\right.$ D Chiara Delli Poggi ${ }^{1}$.llaria Dicembrini ${ }^{1} \cdot$ Matteo Monami $^{1} \cdot$ Edoardo Mannucci $^{1}$
}

Received: 4 April 2021 / Accepted: 29 May 2021 / Published online: 22 June 2021

(c) The Author(s) 2021, corrected publication 2021

\begin{abstract}
Aim To assess the effect on glycaemic control of confinement due to lockdown measures, during COVID-19 pandemic, in people with type 1 (T1DM) and type 2 (T2DM) diabetes.

Methods Meta-analysis of observational studies reporting measures of glucose control and variability before and during and/or after periods of confinement caused by COVID-19 in 2020 and/or 2021.

Results We included 27 studies on T1DM. No significant change in Hbalc was observed after lockdown (WMD - 1.474 $\left.[-3.26 ; 0.31] \mathrm{mmol} / \mathrm{mol}, I^{2}=93.9\right)$. TIR significantly increased during and after lockdown (WMD: $2.731 .47 ; 4.23 \%$, $I^{2}=81 \%$ and $3.73[1.13 ; 5.33] \%, I^{2}=85 \%$, respectively). We retrieved nine studies on T2DM patients. No significant variation in $\mathrm{HbA} 1 \mathrm{c}$ was detected (WMD $-1.257-3.91 ; 1.39 \mathrm{mmol} / \mathrm{mol}, I^{2}=98.3 \%$ ). HbA1c had a more favourable trend in studies performed in Asia than in Europe ( $p=0.022$ between groups).

Conclusion Lockdown showed no significant detrimental effect on HbA1c in either T1DM or T2DM. Conversely, home confinement led to a reduction in mean glucose and glucose variability in T1DM, although with a high heterogeneity of results.
\end{abstract}

Keywords COVID- $19 \cdot$ Diabetes mellitus $\cdot$ Lockdown $\cdot$ Meta analysis

\section{Introduction}

COVID-19 pandemic forced most Countries to adopt confinement measures to prevent the spreading of the disease. Those measures, although different across countries, all led to some extent to a reduction in physical activity, with the shutdown of gyms in many countries; moreover, the commitment to stay at home modified daily routine, increasing the time available for cooking and eating. All those changes in daily routine may have altered glycaemic control in people with diabetes mellitus [1].

The outbreak of COVID-19 during the spring of 2020 and the consequent lockdown in many countries also reduced the access to diabetes specialist care [2], metabolic monitoring

Managed by Antonio Secchi.

Giovanni Antonio Silverii antonio.silverii@gmail.com

1 Diabetes Unit, Experimental and Clinical Biomedical Sciences "Mario Serio" Department, AOU Careggi Hospital, University of Florence, Largo Brambilla 3, 50134 Florence, Italy through laboratory determinations [3], and visits and examinations for screening of diabetic complications. The reduced availability of medical care, associated with insufficient patient self-management [4], was a possible determinant of the observed increase in incidence and severity of diabetic complications, such as foot ulcers [5]. In order to maintain basic care, telemonitoring was implemented in many countries [6-8]. Telematic interactions were also used to help patients in developing coping strategies for managing home confinement [9-11] and maintaining physical activity [12, 13]. Physical activity is crucial in diabetes mellitus management, especially during a pandemic, as it enhances immune response to viral infections [14]; therefore, many efforts have been performed to help patients in finding strategies to maintain it during lockdown [15].

The success of strategies implemented for the care of diabetes during prolonged lockdown for COVID-19 epidemic waves was assessed in several observational studies, providing discordant results [16-18]. This meta-analysis is aimed at collecting all evidence on the effect on glycaemic control of confinement due to lockdown measures, and the consequent adaptation of care, during the first wave of COVID-19 pandemic, in patients with type 1 and type 2 diabetes. 


\section{Materials and methods}

Review Protocol has been submitted for registration to the PROSPERO website CRD42021234360https://www.crd. york.ac.uk/PROSPERO/. Searches were performed in PubMed and Embase ("COVID-19" and "diabetes mellitus") up to March 10, 2021 (see the complete search strings in Supplementary Table 1). Further studies were searched among references from papers.

Observational studies written in English language and performed on humans, enrolling patients with type 1 or type 2 diabetes, and reporting measures of glucose control and variability before and during and/or after periods of confinement caused by COVID-19 in 2021 and/or 2021 were included.

The principal endpoints were variations from baseline in glycated haemoglobin (HbA1c) and Time in Range [19] (TIR, time during which glycaemia is maintained between 70 and $180 \mathrm{mg} / \mathrm{dl}$ ) during and after lockdown. Additional outcomes were Time Above Range (TAR, time during which glycaemia is above $180 \mathrm{mg} / \mathrm{dl}$ ), Time Below Range (TBR, time during which glycaemia is below $70 \mathrm{mg} / \mathrm{dl}$ ), mean glucose, glucose variability (coefficient of variation), frequency of glucose monitoring, variations in eating habits and physical activity, perceived stress.

The following data were extracted: number of included patients, duration of diabetes, mean age, proportion of male patients, patients using flash glucose monitoring (FGM), continuous glucose monitoring (CGM), or self-monitoring of blood glucose (SMBG); proportion of patients in continuous subcutaneous insulin infusion (CSII) multiple daily insulin injections (MDI), basal insulin only, sodium glucose transporter 2 inhibitors (SGLT2i), dipeptiydil-4 inhibitors (DPP-4i), pioglitazone, metformin, sulphonylureas (SU); study duration, country of origin, duration of Lockdown, use of teleconsulting, values of HbA1c before and after lockdown, TIR,TAR, TBR), Coefficient of variability (CV), use of telemedicine, any variation in physical activity, diet, stress. The quality of the studies was assessed at study level, using the scale developed by Carmen-Moga and colleagues (Table 2S).

Titles and abstracts were screened independently by two authors. If one or more inclusion criteria were present, the whole article was read, in order to assess if all the inclusion criteria were present. Study selection, data retrieval and study quality assessment were performed independently by two investigators (C.D.P. and G.A.S.) and conflicts resolved by a third investigator (M.M.).

Begg's and Mandzumkar test were used to detect publication bias, with reference to all principal endpoints; funnel plots were used when more than 10 studies were available for the specific outcome. Weighed mean differences
(WMD) during and after lockdown vs. pre-lockdown), with $95 \%$ confidence intervals, were calculated using random effect models. Rosenthal's conservative estimate of 0.7 [20] was adopted for pre-post correlation. Fixed effect models were used for sensitivity analysis. $I^{2}$ statistics was used for the assessment of heterogeneity. Subgroup analyses were performed, based on country, age group (children and adolescent $<18$ years, adult $>18$ years), type of monitoring (FGM, CGM, SMBG), insulin treatment (multiple injections, continuous subcutaneous infusion, hybrid closed-loop systems), structured telemonitoring (yes/no).

All the analyses were performed on Comprehensive Meta-Analysis Software, V3 edition, Biostat Inc. 14 North Dean Street, Englewood, NJ 07,631, USA.

\section{Results}

Out of 1634 results, 122 studies were selected on the basis of the titles and abstracts. Of those, 79 did not report data on glycaemic control during or after lockdown measures; 6 included both T1DM and T2DM patients without providing subgroup analysis [17]; two studies reported subgroup analyses with no overall analysis [21]. Thirty-six studies reported glycaemic control before and during or after the pandemic restrictions and were therefore included in the meta-analysis (Fig. 1S). Of those, 9 were performed in type 2 diabetes, whereas 27 were performed in type 1 diabetes. Characteristics of the included studies are reported in Table 1.

\section{Type 1 diabetes}

HbAlc. Only 9 studies, enrolling 1174 patients, reported HbA1c before and after lockdown in patients with type 1 diabetes. Mean age was 31.3 years. No significant change in Hba1c was observed after lockdown (WMD - 1.474 [-3.26; 0.31] mmol/mol; Fig. 1 panel A), with relevant heterogeneity $\left(I^{2}=93.9\right)$. No publication bias was detected (Kendall's tau: $16 p=0.1$ ). A subgroup analysis showed that studies with more than $50 \%$ of enrolled patients on continuous glucose monitoring showed a significant decrease in HbA1c (WMD - $3.00[-4.84 ;-1.16] \mathrm{mmol} / \mathrm{mol}$ ), whereas those enrolling more than $50 \%$ patients on SMBG showed no significant variation in $\mathrm{HbA1c}(p=0.003$ for difference between groups; Fig. 5S). Studies performed in Europe showed a significant reduction in HbA1c (WMD - 3.053 $[-3.9 ;-2.2] \mathrm{mmol} / \mathrm{mol})$, whereas those performed in Asia did not (WMD; $2.36[-7.50 ; 12.25] \mathrm{mmol} / \mathrm{mol} ; p<0.0001$ for difference between groups). No significant difference was found in subgroup analyses based on age (Table 4S). 


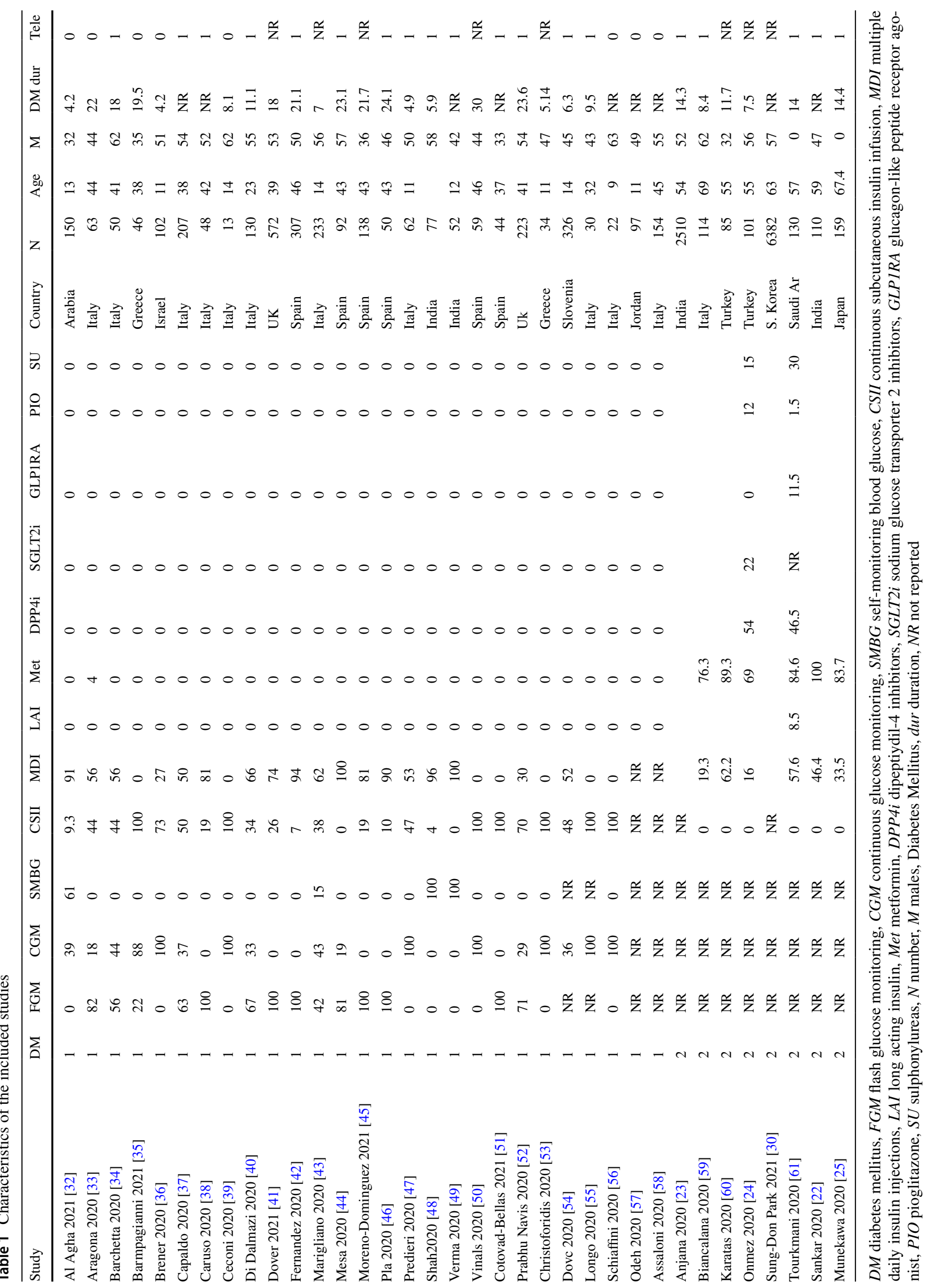




\begin{tabular}{|c|c|c|c|c|c|c|c|c|}
\hline \multirow[t]{2}{*}{ Study name } & \multicolumn{8}{|c|}{ Statistics for each studx } \\
\hline & $\begin{array}{l}\text { Difference } \\
\text { in means }\end{array}$ & $\begin{array}{l}\text { Stand ard } \\
\text { er ror }\end{array}$ & Variance & $\begin{array}{l}\text { Lomer } \\
\text { limit }\end{array}$ & $\begin{array}{c}\text { Upper } \\
\text { limit }\end{array}$ & Z-Val ue & p-Val ue & Total \\
\hline ANAOHa 2081 & $-1,000$ & 1.109 & 1239 & -3.174 & 1.174 & -0.901 & 0.307 & 150 \\
\hline Arso ona 2000 & $-3,000$ & 0,781 & 0,010 & .4530 & $-1,470$ & -3.343 & 0.000 & $\infty$ \\
\hline Fernundez 20000 & $-3,300$ & 0.343 & 0,117 & $-3,972$ & -2.028 & $-9,032$ & 0,000 & 307 \\
\hline Mxrigliano 20200 & .4200 & 0.456 & 0.245 & $-5,170$ & -3200 & -2.48 & 0.000 & 233 \\
\hline$M=502020$ & -2.200 & 0.456 & 0.245 & -3.170 & -1230 & -.4444 & 0.000 & 92 \\
\hline Morena Doming ves 2001 & -4.200 & 0.000 & 0.435 & $-5,492$ & -2.508 & -0.370 & 0.000 & 138 \\
\hline Prodieri 2000 & $-1,000$ & 0.798 & 0,022 & -2545 & 0,545 & .1208 & 0.206 & $\infty$ \\
\hline $\operatorname{Shan} 2000$ & $-.4,900$ & 1,012 & 2,867 & $-8,009$ & $-1,741$ & $-3,041$ & 0,000 & $\pi$ \\
\hline Verma 2020 & 13,000 & 1.205 & 2.387 & 10.910 & 15,900 & 8.522 & 0.000 & 52 \\
\hline & $-1,474$ & 0.910 & 0.227 & -3.257 & 0.306 & $-1,021$ & 0,108 & \\
\hline
\end{tabular}

\section{A: Type 1 Diabetes Mellitus}

Difference in means and $95 \% \mathrm{Cl}$

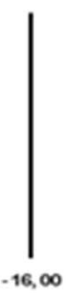

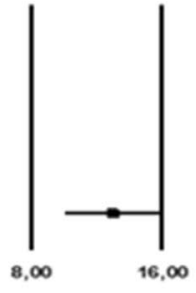

Before Lockdown After Lockdown

\begin{tabular}{|c|c|c|c|c|c|c|c|c|}
\hline \multirow[t]{2}{*}{ Study name } & \multicolumn{8}{|c|}{ Statistics for each study } \\
\hline & $\begin{array}{l}\text { Difference } \\
\text { in means }\end{array}$ & $\begin{array}{l}\text { Standard } \\
\text { error }\end{array}$ & Variance & $\begin{array}{l}\text { Lower } \\
\text { limit }\end{array}$ & $\begin{array}{l}\text { Upper } \\
\text { Iimit }\end{array}$ & z-value & p.Value & Total \\
\hline Agina 2000 & $-5,000$ & Q991 & Q983 & -693 & -3067 & -5043 & $a \propto 00$ & 200 \\
\hline Bncatana 2000 & 2200 & a37 & ave & 1,402 & 2908 & 5841 & $a \omega 0$ & 194 \\
\hline wratescer & 8020 & 1508 & 2225 & 5,004 & 10906 & 5300 & $a 00$ & 86 \\
\hline Ormez 2000 & 4000 & 1906 & 3984 & 000 & 790 & 2004 & aOA5 & 901 \\
\hline 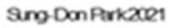 & 0,000 & azt8 & QOAB & $-0<8$ & 0,48 & $Q 000$ & 1000 & 602 \\
\hline Tarhmin 2000 & -18200 & 0989 & $a 97$ & $-20,138$ & -16263 & $-26,412$ & $Q 000$ & 130 \\
\hline Sirkr 2000 & $-1,000$ & Q517 & Q208 & -2013 & 0,013 & -1904 & Q053 & 10 \\
\hline Munckava 2020 & 1800 & QC54 & 0,08 & 0.518 & 302 & 2732 & $a, 06$ & 183 \\
\hline Psama xan & -2000 & Q 445 & $a \times 8$ & -2873 & $-1,127$ & -4400 & $a, 00$ & 300 \\
\hline & -125 & 1362 & 182 & -3906 & 1303 & -0900 & 0363 & \\
\hline
\end{tabular}

\section{B: Type 2 Diabetes Mellitus}

Difference in meons and $95 \% \mathrm{CI}$
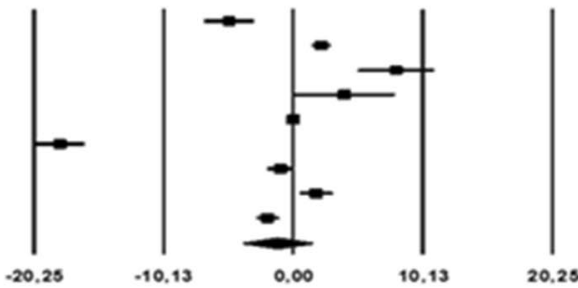

Before Lockdown

After Lockdown

Fig. 1 Difference in HBA1c (mmol/mol), before and after lockdown, in people with T1DM (panel A) and in people with T2DM (panel B)

\section{Time in range}

Nineteen studies, enrolling 1985 patients, and 10 studies, enrolling 1123 patients, reported information on TIR during and after lockdown, respectively. TIR significantly increased during lockdown (WMD: 2.73 [1.47; 4.23]\%; Fig. 2), with high heterogeneity $\left(I^{2}=81 \%\right)$ and no detectable publication bias (Kendall's tau: $0.1, p=0.59$; Fig. $2 \mathrm{~S}$, for funnel plot). Subgroups analyses revealed no difference between studies performed in different countries or in different age groups (Fig. 7S). Meta-regression analysis showed no correlation of TIR variation with its baseline value, or with the proportion of subjects on CSII or MDI (Tab. 4S). Conversely, an inverse correlation was detected between variation in TIR and proportion of men among enrolled subjects (Tab 4S, Fig. 3S). TIR was significantly higher after lockdown (WMD 3.73 [1.13; 5.33] \%; Fig. 8S) with high heterogeneity $\left(I^{2}=85 \%\right)$. No significant publication bias was detected (Kendall's tau: $-7 . p=0.48$ ).

\section{Time above range}

TAR during lockdown and after lockdown was reported in 14 and 9 studies, respectively. TAR was significantly lower both during (WMD: $-1.953[-2.87 ;-1.03] \mathrm{I}^{2}=70$,
Kendall's tau: 7. $p=0.7$; Fig. 9S) and after lockdown (WMD: -3.49 [-0.57; -1.25$] I^{2}=90$ Kendall's tau: 10 . $p=0.21$; Fig. 10S).

\section{Time below range}

Seventeen studies on type 1 diabetes estimated time below range (TBR) before and during lockdown, whereas nine studies reported TBR before and after lockdown: TBR did not change significantly during (WMD: 0.13 [-0.18; 0.43]; $I^{2}: 81 \%$ and Kendall's tau: 0.1, $p=0.59$; Fig. 11S) or after lockdown (WMD: $0.29[-0.28 ; 0.86) ; I^{2}=94$ and Kendall's tau: 12. $p=0.21$; Fig. $12 \mathrm{~S}$ ).

\section{Mean glucose}

In the 14 studies with available data, mean glucose during lockdown was significantly lower than before lockdown (WMD - 2.795 [-4.816; - 0.774]; Fig. 13S), with high heterogeneity $\left(I^{2}=91\right)$ and no evidence of publication bias (Kendall's tau: $-11.0 p=0.54$ ). In addition, mean glucose was significantly lower after lockdown (WMD - 5.29 $[-8.055 ;-2.53]$ with high heterogeneity $\left(I^{2}=87.989\right)$ and 


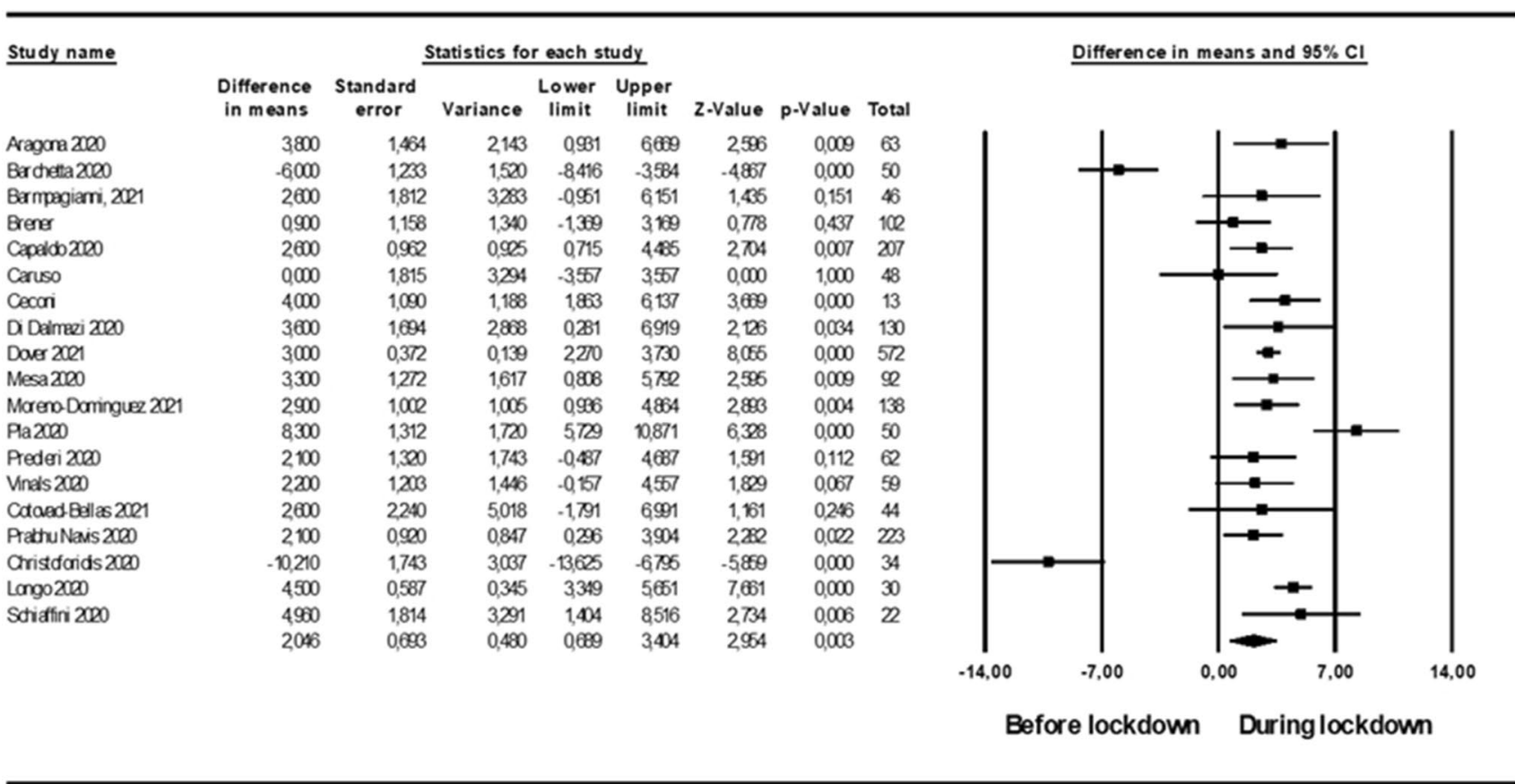

Fig. 2 Difference in time in range (\%), before and during lockdown, in people with T1DM

no evidence of publication bias. (Kendall's tau: $-9 p=0.17$; Fig. 14S).

\section{Glucose coefficient of variation}

Glucose CV during ( $n=16$ studies) and after ( $n=9$ studies) lockdown was significantly reduced (WMD: -0.97 $[-1.48 ;-0.47]$; Fig. $15 \mathrm{~S}$ and $-1.33[-2.11 ;-0.56]$; Fig. 16S, respectively), with no evidence of publication bias (Kendall's tau $=-29.0 ; p=0.27$ ) and high heterogeneity $\left(I^{2}=79\right)$.

\section{Patients' reported behaviours}

Thirteen studies enrolling patients with T1DM reported data on patients' behaviours. The heterogeneity of instruments used for the assessment of patients' behaviour prevented a formal meta-analysis (Table 2). A reduction in physical activity was reported by $8-70 \%$ of patients, whereas those reporting an increase in food intake were $17-46 \%$; moderateto high stress was found in $20-52 \%$ of patients.

\section{Type 2 diabetes}

Nine studies reporting HbA1c before and after lockdown were available in T2DM patients, including 9591 subjects with a median age of 60.5 years; five studies were performed in Asia (India, South Korea, Japan, Saudi Arabia), whereas four were performed in Europe (Turkey, Italy, Greece). No significant variation in $\mathrm{HbA} 1 \mathrm{c}$ was detected (WMD - 1.257 [-3.91; 1.39] mmol/mol; Fig. 1, panel B), with high heterogeneity $\left(I^{2}=98,3 \%\right)$. No significant publication bias was detected (Kendall's tau $=-1, p=0.88$ ). A subgroups analysis revealed a significant difference between studies with mean baseline HbA1c below or above $64 \mathrm{mmol} / \mathrm{mol}$ ( $p=0.045$ between groups), with those with higher baseline HbA1c showing a greater reduction (Fig. 17S). A further subgroup analysis showed that HbA1c had a more favourable trend in studies performed in Asia than in Europe ( $p=0.022$ between groups) (Fig. 18S). No difference was found between age groups ( $p=0.22$ between studies with a mean age higher or lower than 60 years) (Fig. 19S).

Two studies on people with T2DM [22, 23] both performed in India reported a modest reduction (20-24\% of participants) in physical activity with no significant variation in food intake. On the other hand, two studies performed in Turkey and Japan [24, 25] reported a frequent (54-70\% of participants) reduction in physical activity and an increase in food intake (20-55\% of participants). All the three studies reporting data on stress found a moderate increase in perceived stress and anxiety (Table 2). 
Table 2 Characteristics of the included studies

\begin{tabular}{|c|c|c|c|c|c|c|c|c|c|c|c|c|c|c|c|c|}
\hline \multirow[t]{2}{*}{ Study } & \multicolumn{2}{|c|}{$\begin{array}{l}\text { Job modifi- } \\
\text { cations }\end{array}$} & \multicolumn{3}{|c|}{ Physical activity } & \multicolumn{2}{|c|}{$\begin{array}{l}\text { Physical activ- } \\
\text { ity }>30\end{array}$} & \multicolumn{4}{|c|}{ Food intake } & \multicolumn{5}{|l|}{ Stress } \\
\hline & yes & no & var & $\% \uparrow$ & $\% \downarrow$ & before & during & $\% \uparrow$ & $\% \leftrightarrow$ & $\% \downarrow$ & var & scale & var & high & $\bmod$ & low \\
\hline Al Agha 2021 & NR & NR & $\downarrow \downarrow$ & 13 & 66 & 68.5 & NR & $46 \%$ & $54 \%$ & 0 & NR & NR & NR & NR & NR & NR \\
\hline Aragona 2020 & 89 & 11 & NR & NR & NR & NR & 35 & NR & NR & NR & NR & NR & NR & NR & NR & NR \\
\hline Assaloni 2020 & NR & NR & NR & 5 & 8.5 & 90.9 & 82.5 & NR & NR & NR & NR & NR & NR & NR & NR & NR \\
\hline Barchetta 2020 & 48 & 52 & $\downarrow \downarrow$ & NR & NR & 52 & 40 & NR & NR & NR & NR & PSS & NR & 14 & 60 & 26 \\
\hline Capaldo 2020 & NR & NR & $\downarrow \downarrow$ & 19 & 65 & NR & NR & 40 & NR & NR & $\uparrow \uparrow$ & NR & NR & NR & NR & NR \\
\hline Caruso 2020 & 48 & 52 & $\downarrow \downarrow$ & 12 & 70 & NR & NR & 42 & 58 & NR & $\uparrow \uparrow$ & GHQ-12 & NR & 50 & & 50 \\
\hline Di Dalmazi 2020 & NR & NR & \multicolumn{5}{|c|}{ IPAQ: 1680 METS during lockdown } & NR & NR & NR & NR & \multicolumn{5}{|c|}{ PSS: 14.5 during lockdown } \\
\hline Pla 2020 & 48 & 52 & $\leftrightarrow$ & NR & NR & NR & 46 & NR & NR & NR & NR & $\mathrm{NR}$ & $\uparrow$ & 36 & 16 & 48 \\
\hline Predieri 2020 & NR & NR & $\downarrow \downarrow \downarrow$ & NR & NR & NR & NR & NR & NR & NR & NR & NR & NR & NR & NR & NR \\
\hline Verma 2020 & 38 & 62 & $\downarrow$ & 6 & 37 & NR & NR & 17.4 & 82.6 & NR & $\leftrightarrow$ & NR & NR & 11.5 & 9.6 & 78.9 \\
\hline Longo 2020 & 97 & 3 & NR & NR & NR & NR & 20 & NR & NR & NR & $\uparrow$ & NR & NR & NR & NR & NR \\
\hline Anjana 2020 & NR & NR & $\downarrow$ & 14 & $24 \%$ & NR & NR & NR & 88 & NR & $\uparrow$ & NR & NR & NR & NR & NR \\
\hline Onmez 2020 & 17 & NR & $\downarrow \downarrow$ & NR & 70 & NR & NR & $55 \%$ & 45 & 0 & $\uparrow \uparrow$ & NR & NR & NR & NR & NR \\
\hline Sankar 2020 & 18 & NR & $\downarrow$ & 3 & $15 \%$ & NR & NR & 25 & 12 & 63 & $\downarrow$ & NR & $\uparrow$ & 15 & 37 & 52 \\
\hline Munekawa 2020 & NR & NR & $\downarrow \downarrow$ & NR & 51.4 & 66 & NR & 20 & 80 & NR & $\uparrow \uparrow$ & VAS & $\uparrow$ & 41.8 & NR & NR \\
\hline
\end{tabular}

Physical activity $>30=$ Physical activity for more than 30 min every day, $N R$ not reported, var variations, job modifications $=$ either remote working or job loss, mod moderate, PSS perceived stress scale, IPAQ international physical activity questionnaire-short form, MET metabolic equivalent, GHQ-12 general health questionnaire-12 items arrows, $\downarrow=$ slight reduction, $\downarrow \downarrow=$ consistent reduction, $\downarrow \downarrow \downarrow=$ massive reduction, $\leftrightarrow=$ no substantial variation, $\uparrow=$ slight increase, $\uparrow \uparrow=$ consistent increase

\section{Discussion}

Most studies on the glycaemic effects of lockdown were performed in T1DM, usually in patients using either FGM or CGM. The assessment of variations in interstitial glucose can be performed in a shorter time than that required for exploring modifications in $\mathrm{HbA} 1 \mathrm{c}$. For this reason, we already have a substantial body of evidence on the effects of lockdown during the first pandemic wave in T1DM, but not in T2DM.

In T1DM, an improvement in glycaemic control during lockdown was observed, together with a reduction in glucose variability. These results were obtained despite an observed reduction in physical activity and dietary compliance during lockdown, determined by the increased time spent at home; in addition, access to care was impaired during lockdown [26], and surveys on perceived glucose control revealed a high perceived difficulty in dealing with COVID-19 restrictions in people with T1DM [27].

The interpretation of results on glucose control in T1DM is problematic because of their high heterogeneity. The exploration of moderators of lockdown effect, using either subgroup analyses of trials or meta-regression, provides some further insight. Lockdown seems to have produced a greater beneficial effect on females than in males. This is consistent with a Chinese study in which males with T1DM had poorer glycaemic control than females during
COVID-19 lockdown [28]; previous findings showed that females with DM, when compared to males, elicited more frequently behaviours aimed at disease prevention, health promotion and symptom recognition [29], which could have been of help in coping with confinement. An increase in glucose monitoring and an improvement in insulin titration during remote working or remote schooling may explain these improvement, as suggested by a study showing an improvement in glucose control only in patients working at home [21]; unfortunately, the information on glucose monitoring and on the proportion of patients on home schooling or working was insufficient to add these variables as moderators. Notably, in studies enrolling a majority of patients with T1DM with interstitial glucose monitoring systems, HbA1c was significantly reduced, suggesting that FGM or CGM could have been a relevant support during confinement. The difference in effects of lockdown between Asian and European studies could have been determined by the different proportion of patients on FGM/CGM (substantially higher in European studies), or to differences in lockdown measures (usually stricter in European countries).

No significant beneficial or detrimental effect of lockdown on glucose control was found in Type 2 diabetes, although the limited number and high heterogeneity of available studies suggests caution in drawing definitive conclusions. In patients with T2DM, studies performed in Asia showed a significant reduction in $\mathrm{HbA} 1 \mathrm{c}$, which was not 
observed in European studies. This geographic difference could have been determined by the differences in confinement measures (much stricter in Europe than in some Asian countries such as South Korea [30]), or by cultural differences possibly affecting the effect of lockdown on diet and physical activity; in studies performed in India, for example, lockdown appeared to have only a minor effect on physical activity $[22,23]$.

Some limitations of the present meta-analysis should be recognized. Centers performing the studies were often thirdlevel clinics, which are not representative of all diabetes care facilities, because of a possible wider use of telemedicine, continuous glucose monitoring and more advanced treatments. Most of the studies performed in T1DM patients, furthermore, only enrolled patients which had performed at least $70 \%$ scans, thus excluding less compliant patients, who may be at higher risk of glucose deterioration. In addition, in our metanalysis, the mean age of the included patients with T2DM was low; accordingly, a survey has shown that patients contacted for telemedicine by a diabetes clinic during the pandemic were younger, with shorter disease duration and a lower prevalence of complications than the average pre-lockdown patients [31].

In conclusion, lockdown showed no significant detrimental effect on HbA1c in either T1DM or T2DM. Conversely, home confinement during the first pandemic wave led to a reduction in mean glucose and glucose variability in T1DM, although further studies are needed to better understand the high heterogeneity of results.

Supplementary Information The online version contains supplementary material available at https://doi.org/10.1007/s00592-021-01754-2.

\begin{abstract}
Author contribution GAS and EM were involved in each of the following points: 1. Design. 2. Data collection. 3. Analysis. 4. Writing manuscript. CDP, ID and MM were involved in each of the following points: 1. Data Collection 2. Manuscript revision.
\end{abstract}

Funding Open access funding provided by Università degli Studi di Firenze within the CRUI-CARE Agreement. This research was performed as a part of the institutional activity of the unit, with no specific funding. All expenses, including salaries of the investigators, were covered by public research funds assigned to the unit. The manuscript was drafted and revised by the authors in accordance with ICJME standards for authorship. The corresponding author had full access to all the data in the study and had final responsibility for the decision to submit for publication.

\section{Declarations}

Conflict of interest GAS and ID have received speaking fees from Astra Zeneca, Novonordisk, Eli Lilly outside the submitted work; CDP has no conflict of interest; MM has received speaking fees from Astra Zeneca, Bristol Myers Squibb, Boehringer-Ingelheim, Eli-Lilly, Merck, Novo Nordisk, Sanofi and Novartis and research grants from Bristol Myers Squibb outside the submitted work; EM has received consultancy fees from Merck and Novartis speaking fees from Astra
Zeneca, Bristol Myers Squibb, Boehringer-Ingelheim, Eli-Lilly, Merck, Novo Nordisk, Sanofi and Novartis and research grants from Merck, Novartis and Takeda outside the submitted work. All the authors approved the final version of this manuscript. Dr. Giovanni Antonio Silverii is the person who takes full responsibility for the work as a whole, including the study design, access to data and the decision to submit and publish the manuscript.

Ethical approval This article does not contain any studies with human participants or animals performed by any of the authors.

Informed consent For this type of study formal consent is not required.

Open Access This article is licensed under a Creative Commons Attribution 4.0 International License, which permits use, sharing, adaptation, distribution and reproduction in any medium or format, as long as you give appropriate credit to the original author(s) and the source, provide a link to the Creative Commons licence, and indicate if changes were made. The images or other third party material in this article are included in the article's Creative Commons licence, unless indicated otherwise in a credit line to the material. If material is not included in the article's Creative Commons licence and your intended use is not permitted by statutory regulation or exceeds the permitted use, you will need to obtain permission directly from the copyright holder. To view a copy of this licence, visit http://creativecommons.org/licenses/by/4.0/.

\section{References}

1. Grabia M, Markiewicz-Żukowska R, Puścion-Jakubik A et al (2020) The nutritional and health effects of the COVID-19 pandemic on patients with diabetes mellitus. Nutrients 12(10):1-15

2. Khader MA, Jabeen T, Namoju R (2020) A cross sectional study reveals severe disruption in glycemic control in people with diabetes during and after lockdown in India. Diabetes Metab Syndr 14(6):1579-1584

3. Fragala MS, Kaufman HW, Meigs JB, Niles JK, McPhaul MJ (2020) Consequences of the COVID-19 pandemic: reduced hemoglobin A1c diabetes monitoring. Popul Health Manag 24(1):8-9

4. Bala R, Srivastava A, Potsangbam T, Anal L, Ningthoujam GD (2021) Self care practices and psychological distress among diabetic patients in Manipur during COVID-19: a scenario from the North East. Diabetes Metab Syndr Clin Res Rev 15(1):93-98

5. Jaly I, Iyengar K, Bahl S, Hughes T, Vaishya R (2020) Redefining diabetic foot disease management service during COVID-19 pandemic. Diabetes Metab Syndr 14(5):833-838

6. Pintaudi B, Garavaglia G, Disoteo OE et al (2021) First televisits provided by the public health system for patients affected by diabetes mellitus in COVID-19 pandemic. Diabetes Res Clin Pract $p$ 108697

7. Alromaihi D, Alamuddin N, George S (2020) Sustainable diabetes care services during COVID-19 pandemic. Diabetes Res Clin Pract 166:108298

8. Jones MS, Goley AL, Alexander BE, Keller SB, Caldwell MM, Buse JB (2020) Inpatient transition to virtual care during COVID19 pandemic. Diabetes Technol Ther 22(6):444-448

9. de Mattos Matheus AS, Cabizuca CA, Tannus LRM et al (2020) Telemonitoring type 1 diabetes patients during the COVID-19 pandemic in Brazil: was it useful? Arch Endocrinol Metab. https:// doi.org/10.20945/2359-3997000000309 (Epub ahead of print)

10. Rachmiel M, Lebenthal Y, Mazor-Aronovitch K et al (2021) Glycaemic control in the paediatric and young adult population with type 1 diabetes following a single telehealth visit-what have we 
learned from the COVID-19 lockdown? Acta Diabetol 58(6):697705 (Epub 2021 Jan 28)

11. Boscari F, Ferretto S, Uliana A, Avogaro A, Bruttomesso D (2021) Efficacy of telemedicine for persons with type 1 diabetes during Covid19 lockdown. Nutr Diabetes 11(1):1-5

12. Fatyga E, Dzięgielewska-Gęsiak S, Wierzgoń A, Stołtny D, MucWierzgoń M (2020) The coronavirus disease 2019 pandemic: telemedicine in elderly patients with type 2 diabetes. Pol Arch Intern Med 130(5):452-454 (Epub 2020 May 9)

13. Kiran T, Moonen G, Bhattacharyya OK et al (2020) Managing type 2 diabetes in primary care during COVID-19. Can Fam Physician 66(10):745-747

14. Balducci S, Coccia EM (2020) Sedentariness and physical activity in type 2 diabetes during the COVID-19 pandemic. Diabetes Metab Res Rev pp 14-15

15. Marçal IR, Fernandes B, Viana AA, Ciolac EG (2020) The urgent need for recommending physical activity for the management of diabetes during and beyond COVID-19 outbreak. Front Endocrinol (Lausanne). https://doi.org/10.3389/fendo.2020.584642

16. Batten L, Chandrajay D, Burkinshaw C, Gill J, Jayagopal V (2021) Service restriction during the COVID-19 pandemic and its impact on HbA1c: a surprising outcome. Diabet Med 38(1):1-2

17. Maddaloni E, Coraggio L, Pieralice S, Carlone A, Pozzilli P, Buzzetti R (2020) Effects of covid-19 lockdown on glucose control: continuous glucose monitoring data from people with diabetes on intensive insulin therapy. Diabetes Care 43(8):e86-e87

18. Jethwani P, Saboo B, Jethwani L et al (2020) Management of children and adolescents having type 1 diabetes during COVID-19 pandemic in India: challenges and solutions. Int J Diabetes Dev Ctries 40(3):335-339

19. Wilmot EG, Lumb A, Hammond $P$ et al (2021) Time in range: a best practice guide for UK diabetes healthcare professionals in the context of the COVID-19 global pandemic. Diabet Med 38(1):e14433

20. Rosenthal R (1995) Writing meta-analytic reviews. Psychol Bull 118(2):183-192

21. Bonora BM, Boscari F, Avogaro A, Bruttomesso D, Fadini GP (2020) Glycaemic control among people with Type 1 diabetes during lockdown for the SARS-CoV-2 outbreak in Italy. Diabetes Ther 11(6):1369-1379

22. Sankar P, Ahmed WN, Mariam Koshy V, Jacob R, Sasidharan S (2020) Effects of COVID-19 lockdown on type 2 diabetes, lifestyle and psychosocial health: a hospital-based cross-sectional survey from South India. Diabetes Metab Syndr 14(6):1815-1819 (Epub 2020 Sep 11)

23. Anjana RM, Pradeepa R, Deepa M et al (2020) Acceptability and utilization of newer technologies and effects on glycemic control in type 2 diabetes: lessons learned from lockdown. Diabetes Technol Ther 22(7):527-534

24. Önmez, Gamsızkan Z, Özdemir Ş A et al (2020) The effect of COVID-19 lockdown on glycemic control in patients with type 2 diabetes mellitus in Turkey. Diabetes Metab Syndr Clin Res Rev 14(6):1963-1966

25. Munekawa C, Hosomi Y, Hashimoto Y et al (2021) Effect of coronavirus disease 2019 pandemic on the lifestyle and glycemic control in patients with type 2 diabetes: a cross-section and retrospective cohort study. Endocr J 68(2):201-210

26. Kluge HHP, Wickramasinghe K, Rippin HL et al (2020) Prevention and control of non-communicable diseases in the COVID-19 response. Lancet (London, England) 395(10238):1678-1680

27. Fisher L, Polonsky W, Asuni A, Jolly Y, Hessler D (2020) The early impact of the COVID-19 pandemic on adults with type 1 or type 2 diabetes: a national cohort study. J Diabetes Complicat 34(12):107748 (Epub 2020 Oct 7)
28. Tao J, Gao L, Liu Q et al (2020) Factors contributing to glycemic control in diabetes mellitus patients complying with home quarantine during the coronavirus disease 2019 (COVID-19) epidemic. Diabetes Res Clin Pract 170:108514

29. Caruso R, Rebora P, Luciani M, Di Mauro S, Ausili D (2020) Sex-related differences in self-care behaviors of adults with type 2 diabetes mellitus. Endocrine 67(2):354-362

30. Park SD, Kim SW, Moon JS et al (2021) Impact of social distancing due to coronavirus disease 2019 on the changes in glycosylated hemoglobin level in people with type 2 diabetes mellitus. Diabetes Metab J 45(1):109-114

31. Bonora BM, Morieri ML, Avogaro A, Fadini GP (2021) The toll of lockdown against COVID-19 on diabetes outpatient care: analysis from an outbreak area in Northeast Italy. Diabetes Care 44(1):e18-e21

32. Al Agha AE, Alharbi RS, Almohammadi OA, Yousef SY, Sulimani AE, Alaama RA (2021) Impact of COVID-19 lockdown on glycemic control in children and adolescents. Saudi Med J 42(1):44-48

33. Aragona M, Rodia C, Bertolotto A et al (2020) Type 1 diabetes and COVID-19: the "lockdown effect." Diabetes Res Clin Pract 170:108468

34. Barchetta I, Agata F, Bertoccini L, Ceccarelli V (2020) Effects ofwork status changes and perceived stress on glycaemic control in individuals with type 1 diabetes during COVID-19 lockdown in Italy. Diabetes Res Clin Pract 170:108513

35. Barmpagianni A, Lambadiari V, Papazafiropoulou A et al (2021) Glycemic control of patients with type 1 diabetes using an insulin pump before and during the COVID-19-associated quarantine. Diabetes Technol Ther 23(4):320-321 (Epub 2020 Nov 23)

36. Brener A, Mazor-Aronovitch K, Rachmiel M et al (2020) Lessons learned from the continuous glucose monitoring metrics in pediatric patients with type 1 diabetes under COVID-19 lockdown. Acta Diabetol 57(12):1511-1517

37. Capaldo B, Annuzzi G, Creanza A et al (2020) Blood glucose control during lockdown for COVID-19: Cgm metrics in Italian adults with type 1 diabetes. Diabetes Care 43(8):e88-e89

38. Caruso I, Di Molfetta S, Guarini F et al (2020) Reduction of hypoglycaemia, lifestyle modifications and psychological distress during lockdown following SARS-CoV-2 outbreak in type 1 diabetes. Diabetes Metab Res Rev pp 1-7

39. Ceconi V, Barbi E, Tornese G (2020) Glycemic control in type 1 diabetes mellitus and COVID-19 lockdown: what comes after a 'quarantine'? J Diabetes 12(12):946-948

40. Di Dalmazi G, Maltoni G, Bongiorno C et al (2020) Comparison of the effects of lockdown due to COVID-19 on glucose patterns among children, adolescents, and adults with type 1 diabetes: CGM study. BMJ Open Diabetes Res Care 8(2):e001664

41. Dover AR, Ritchie SA, McKnight JA et al (2021) Assessment of the effect of the COVID-19 lockdown on glycaemic control in people with type 1 diabetes using flash glucose monitoring. Diabet Med 38(1):e14374

42. Fernández E, Cortazar A, Bellido V (2020) Impact of COVID-19 lockdown on glycemic control in patients with type 1 diabetes. Diabetes Res Clin Pract 166:108348

43. Marigliano M, Maffeis C (2021) Glycemic control of children and adolescents with type 1 diabetes improved after COVID-19 lockdown in Italy. Acta Diabetol 58(5):661-664 (Epub 2021 Feb 2)

44. Mesa A, Viñals C, Pueyo I et al (2020) The impact of strict COVID-19 lockdown in Spain on glycemic profiles in patients with type 1 diabetes prone to hypoglycemia using standalone continuous glucose monitoring. Diabetes Res Clin Pract 167:108354

45. Moreno-Domínguez Ó, de Villar NGP, Barquiel B et al (2021) Factors related to improvement of glycemic control among adults 
with type 1 diabetes during lockdown due to COVID-19. Diabetes Technol Ther 23(5):399-400 (Epub 2020 Dec 8)

46. Pla B, Arranz A, Knott C et al (2020) Impact of COVID-19 lockdown on glycemic control in adults with type 1 diabetes mellitus. J Endocr Soc 4(12):1-8

47. Predieri B, Leo F, Candia F et al (2020) Glycemic control improvement in Italian children and adolescents with type 1 diabetes followed through telemedicine during lockdown due to the COVID-19 pandemic. Front Endocrinol (Lausanne) 11:595735

48. Shah N, Karguppikar M, Bhor S, Ladkat D, Khadilkar V, Khadilkar A (2021) Impact of lockdown for COVID-19 pandemic in Indian children and youth with type 1 diabetes from different socio-economic classes. J Pediatr Endocrinol Metab 34(2):217-223

49. Verma A, Rajput R, Verma S, Balania VKB, Jangra B (2020) Impact of lockdown in COVID 19 on glycemic control in patients with type 1 diabetes mellitus. Diabetes Metab Syndr Clin Res Rev 14(January):1213-1216

50. Viñals C, Mesa A, Roca D et al (2021) Management of glucose profile throughout strict COVID-19 lockdown by patients with type 1 diabetes prone to hypoglycaemia using sensor-augmented pump. Acta Diabetol 58(3):383-388 (Epub 2020 Oct 30)

51. Cotovad-Bellas L, Tejera-Pérez C, Prieto-Tenreiro A, SánchezBao A, Bellido-Guerrero D (2020) The challenge of diabetes home control in COVID-19 times: proof is in the pudding. Diabetes Res Clin Pract 168:108379

52. Prabhu Navis J, Leelarathna L, Mubita W et al (2021) Impact of COVID-19 lockdown on flash and real-time glucose sensor users with type 1 diabetes in England. Acta Diabetol 58(2):231-237 (Epub 2020 Oct 16)

53. Christoforidis A, Kavoura E, Nemtsa A, Pappa K, Dimitriadou M (2020) Coronavirus lockdown effect on type 1 diabetes management on children wearing insulin pump equipped with continuous glucose monitoring system. Diabetes Res Clin Pract 166:108307

54. Dovc K, Osredkar SR, Schweiger DS, Battelino T, Bratina N (2020) Nationwide digital/virtual diabetes care of children, adolescents and young adults with type 1 diabetes during a covid19 pandemic in Slovenia. Zdr Vestn 89(11-12):626-633

55. Longo M, Caruso P, Petrizzo M, Castaldo F (2020) Glycemic control in people with type 1 diabetes using a hybrid closed loop system and followed by telemedicine during the COVID-19 pandemic in Italy. Diabetes Res Clin Pract 169:108440

56. Schiaffini R, Barbetti F, Rapini N et al (2020) School and preschool children with type 1 diabetes during Covid-19 quarantine: the synergic effect of parental care and technology. Diabetes Res Clin Pract 166:108302

57. Odeh R, Gharaibeh L, Daher A, Kussad S, Alassaf A (2020) Caring for a child with type 1 diabetes during COVID-19 lockdown in a developing country: challenges and parents' perspectives on the use of telemedicine. Diabetes Res Clin Pract 168:108393

58. Assaloni R, Carnevale V, Puci MV, Ferraro OE (2020) Coronavirus disease (Covid-19): how does the exercise practice in active people with type 1 diabetes change? A preliminary survey. Diabetes Res Clin Pract 166:108297

59. Biancalana E, Parolini F, Mengozzi A, Solini A (2021) Short-term impact of COVID-19 lockdown on metabolic control of patients with well-controlled type 2 diabetes: a single-centre observational study. Acta Diabetol 58(4):431-436 (Epub 2020 Nov 21)

60. Karatas S, Yesim T, Beysel S (2021) Impact of lockdown COVID19 on metabolic control in type 2 diabetes mellitus and healthy people. Prim Care Diabetes S1751-9918(21):00003-00006. https://doi.org/10.1016/j.pcd.2021.01.003 (Epub ahead of print)

61. Tourkmani AM, ALHarbi TJ, Rsheed AMB et al (2021) The impact of telemedicine on patients with uncontrolled type 2 diabetes mellitus during the COVID-19 pandemic in Saudi Arabia: findings and implications. J Telemed Telecare. https://doi.org/10. 1177/1357633X20985763 (Epub ahead of print)

Publisher's Note Springer Nature remains neutral with regard to jurisdictional claims in published maps and institutional affiliations. 